\title{
16-QAM Field-Quadrature Decomposition using Polarization-Assisted Phase Sensitive Amplification
}

Kjøller, Niels-Kristian; Piels, Molly; Da Ros, Francesco; Dalgaard, Kjeld; Galili, Michael; Oxenløwe, Leif Katsuo

\section{Published in:}

Proceedings of the 2016 IEEE Photonics Conference

Publication date:

2016

Document Version

Peer reviewed version

Link back to DTU Orbit

Citation (APA):

Kjøller, N-K., Piels, M., Da Ros, F., Dalgaard, K., Galili, M., \& Oxenløwe, L. K. (2016). 16-QAM Field-Quadrature Decomposition using Polarization-Assisted Phase Sensitive Amplification. In Proceedings of the 2016 IEEE Photonics Conference IEEE Press.

\section{General rights}

Copyright and moral rights for the publications made accessible in the public portal are retained by the authors and/or other copyright owners and it is a condition of accessing publications that users recognise and abide by the legal requirements associated with these rights.

- Users may download and print one copy of any publication from the public portal for the purpose of private study or research.

- You may not further distribute the material or use it for any profit-making activity or commercial gain

- You may freely distribute the URL identifying the publication in the public portal 


\title{
16-QAM Field-Quadrature Decomposition using Polarization-Assisted Phase Sensitive Amplification
}

\author{
N. K. Kjøller, M. Piels, F. Da Ros, K. Dalgaard, M. Galili and L. K. Oxenløwe \\ DTU Fotonik, Technical University of Denmark. DK-2800 Kgs. Lyngby, Denmark.
}

\begin{abstract}
Simultaneous I and Q extraction for 16-QAM is experimentally demonstrated through field-quadrature decomposition using a polarization-assisted phase sensitive amplifier. The quadrature components are successfully received and performance is evaluated through bit-error-ratio testing.
\end{abstract}

Keywords-optical signal processing; phase sensitive amplification; polarization-assisted phase sensitive amplification

\section{INTRODUCTION}

The use of spectrally efficient multilevel modulation formats such as m-level phase-shift keying (PSK) or quadrature amplitude modulation (QAM) has increased steadily in recent years. Nonlinear all-optical signal processing of such advanced modulation formats has attracted much attention, with the potential of energy and cost reductions over electronic processing [1]. Advantages include broad optical bandwidths and femtosecond response times, enabling ultrafast processing operations such as signal regeneration, wavelength conversion, and format conversion [2]. Electric field quadrature decomposition, extracting the in-phase (I) and quadrature (Q) components of an optical signal, is a useful operation for QAM modulated signals with possible applications in modulation format conversion. For 16-QAM it constitutes a building block towards conversion to four binary signals which would allow real-time direct-detection, or possibly alloptical regeneration through amplitude regeneration and coherent addition of the decomposed parts. Polarizationassisted phase sensitive amplification (PA-PSA) has been established as an effective technique for field quadrature decomposition, with demonstrated applications in regeneration of BPSK and QPSK signals and quadrature decomposition of QPSK signals [3-5].

In this paper we expand the application of PA-PSA and demonstrate experimentally the decomposition of a 16-

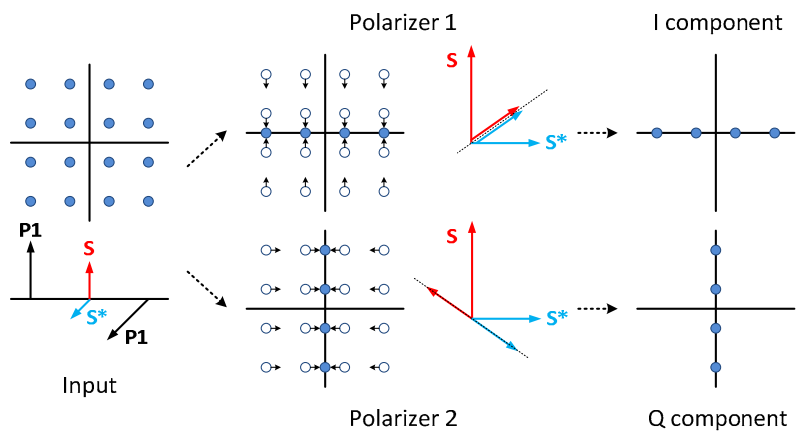

Fig. 1. Field-quadrature decomposition of a 16-QAM signal.

QAM signal, separating its I and Q components. Simultaneous extraction of the $\mathrm{I}$ and $\mathrm{Q}$ components is verified and bit-error-rate (BER) performance is evaluated for the decomposed signals.

\section{PRINCIPLE}

As demonstrated in [3-5], PA-PSA involves coherently mixing the signal and idler of a dual pump degenerate vector PSA in a polarizer, as shown in Fig. 1. By adjusting the transmission axis of the polarizer, the signal (S) and its phase conjugated idler $\left(\mathrm{S}^{*}\right)$ are added or subtracted with equal amplitude in order to yield the I or Q component of the signal. For 16-QAM the resulting outputs are modulated in a format having two amplitude levels $\left(\frac{1}{2}\right.$ and $\frac{3}{2}$ of the average output amplitude) and two phase levels ( 0 and $\pi$ ). This format will be referred to as 4 amplitude-phase-shift keying (4-APSK).

\section{EXPERIMENTAL DEMONSTRATION AND RESUlTS}

In order to investigate the performance experimentally, the setup in Fig. 2 was constructed. Three phase-locked carriers P1 $(1538 \mathrm{~nm}), \mathrm{S}(1544 \mathrm{~nm})$, and P2 (1550 nm) to be used

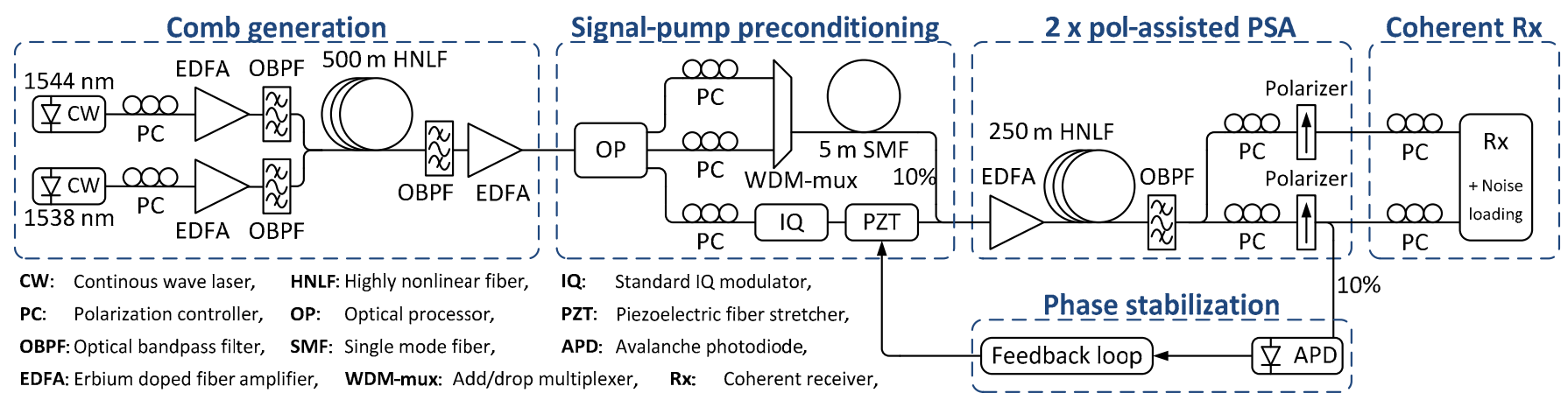

Fig. 2. Experimental setup for 16-QAM field-quadrature decomposition using polarization-assisted phase sensitive amplification. 
a)

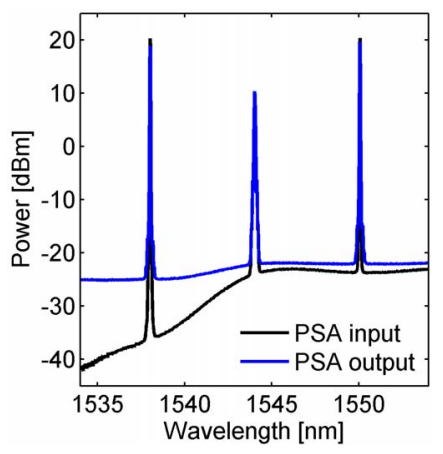

b)

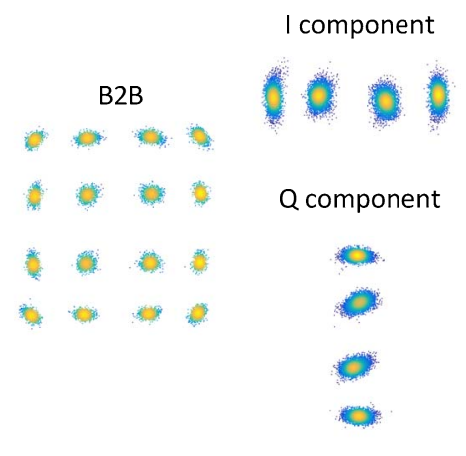

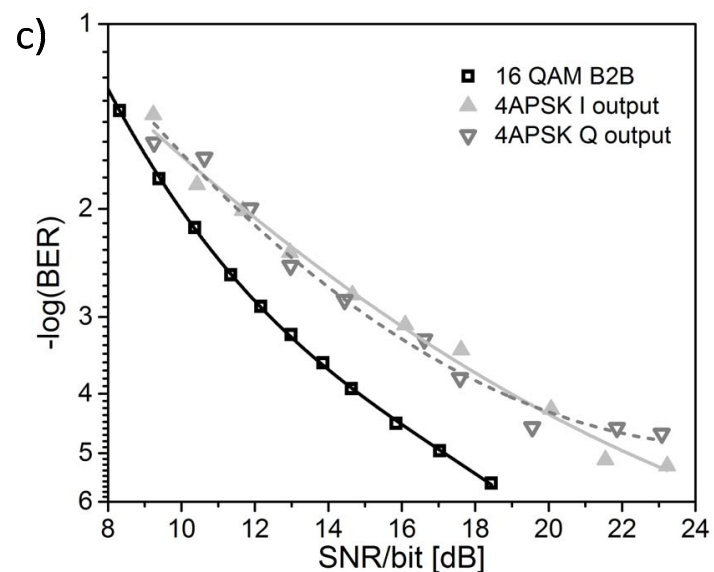

Fig. 3. Experimental results. (a) Input/output spectra of the PSA. (b) System input/output constellation diagrams. (c) BER curves for the back-to-back (B2B) signal and for the decomposed I and Q outputs.

for the PSA stage are generated using four wave mixing in a $500 \mathrm{~m}$ highly nonlinear fiber with stable phase-matching for improved non-linear efficiency (HNLF-SPINE). The signal carrier $\mathrm{S}$ and the pumps $\mathrm{P} 1, \mathrm{P} 2$ are separated using an optical processor. $\mathrm{S}$ is modulated at $10 \mathrm{GBd}$ with a 16-QAM signal consisting of pseudo-random bit sequences (PRBSs) of lengths $2^{11}-1$ and $2^{15}-1$ in the $I$ and $Q$ components, using a standard IQ modulator. The signal and pumps are recombined and their polarizations are adjusted so that $\mathrm{P} 1$ and $\mathrm{S}$ are parallel and orthogonal to $\mathrm{P} 2$. The separate path lengths are equalized by inserting $\sim 5 \mathrm{~m}$ of standard single mode fiber. Slow thermal drifts of the relative phases are compensated by an active feed-back phase-control loop based on a low speed avalanche photodiode and a piezoelectric actuator. PSA takes place in a strained $250 \mathrm{~m}$ HNLF-SPINE, with the input and output spectra shown in Fig. 3(a). A total input power of $24 \mathrm{dBm}$ and a pump to signal power ratio of $10 \mathrm{~dB}$ results in the creation of a phase conjugated idler with a conversion efficiency of $-5.1 \mathrm{~dB}$. The pumps are removed using an optical bandpass filter and the orthogonal signal-idler pair is mixed simultaneously in two polarizers aligned to yield the I and Q components. A static phase sensitive extinction ratio of $22.8 \mathrm{~dB}$ is observed. The two outputs are passed through a noise loading stage to a coherent receiver and digital storage oscilloscope for offline signal processing. This consisted of clock recovery, radius-directed adaptive equalization using the cost function modification suggested in [7], and carrier recovery using a decision-directed phase-locked loop.

In Fig. 3(b) the measured constellation diagrams are shown for the 16-QAM input and the decomposed I and Q outputs. After quadrature decomposition the $2^{11}-1$ and $2^{15}-1$ PRBSs are recovered on the I and Q components respectively, verifying simultaneous extraction of both I and Q. BER is measured for the 16-QAM input B2B (black) and for the 4-APSK modulated I and Q outputs (grey), as seen in Fig. 3(c). For each point a total of $2.4 \mathrm{e} 6$ symbols are counted, allowing estimation of BERs down to $10^{-5}$ with at least 100 counted errors. Points have been included below $\mathrm{BER}=10^{-5}$ with error counts down to 13 , corresponding to $99 \%$ probability for the actual BER being within a factor of two [8]. We observe that the field-quadrature decomposition results in a penalty of the SNR required for $\mathrm{BER}=10^{-2}$ of around $1.5 \mathrm{~dB}$, increasing to around $5 \mathrm{~dB}$ for the $\mathrm{I}$ and $6 \mathrm{~dB}$ for the $\mathrm{Q}$ components for $\mathrm{BER}=10^{-5}$.

\section{CONCLUSION}

We have expanded the application of polarizationassisted phase sensitive amplification, and demonstrated electric field-quadrature decomposition of a 16-QAM signal at $10 \mathrm{GBd}$. We successfully extract the two quadrature components (I and Q) simultaneously. The BER performance have been evaluated and we report SNR penalties of $1.5 \mathrm{~dB}$ at $\mathrm{BER}=10^{-2}$, increasing to $5 \mathrm{~dB}$ for the $\mathrm{I}$ and $6 \mathrm{~dB}$ for the $\mathrm{Q}$ components at $\mathrm{BER}=10^{-5}$.

\section{ACKNOWLEDGMENT}

Danish Council for Independent Research (FTP) for funding the TOR project (grant no. 12-127224), and OFS Fitel Denmark ApS for providing the HNLF-SPINEs.

\section{REFERENCES}

[1] S. Namiki et al., "Ultrahigh-definition video transmission and extremely green optical networks for future," IEEE J. Sel. Top. Quantum Electron., vol. 17, no. 2, pp. 446-457, March/April 2011.

[2] S. Wabnitz and B. J. Eggleton, All-Optical Signal Processing - Data Communication and Storage Applications, Springer Series in Optical Sciences vol. 194. Springer: Cham, Switserland, 2015.

[3] F. Parmigiani et al., "Polarization-Assisted Phase-Sensitive Processor," J. Lightwave Technol., vol. 33, no. 6, pp. 1166-1174, March 2015.

[4] A. Lorences-Riesgo et al., "Quadrature demultiplexing using a degenerate vector parametric amplifier," Opt. Exp., vol. 22, no. 24, pp. 29424-29434, December 2014.

[5] N. K. Kjøller et al., "Quadrature Decomposition by Phase Conjugation and Projection in a Polarizing Beam Splitter," in Proc. Eur. Conf. Opt. Commun. (ECOC), paper P.3.8, September 2014.

[6] J. G. Proakis, Communication Systems Engineering, 2nd ed. Prentice Hall: Upper Saddle River, New Jersey, 2002, pp. 405-436.

[7] E. Pincemin et al., "Novel blind equalizer for coherent DP-BPSK transmission systems: Theory and experiment," IEEE Photon. Technol. Lett., vol. 22, no. 18, pp. 1835-1838, September 2013.

[8] M. C. Jeruchim, "Techniques for estimating the bit error rate in the simulation of digital communication systems," IEEE J. Sel. Areas Commun., vol. 2, no. 1, pp. 153-170, January 1984. 